\title{
SELECTED TOPICS ON DATA ANALYSIS IN ASTRONOMY
}


This page is intentionally left blank 


\section{SELECTED TOPICS ON DATA ANALYSIS IN ASTRONOMY}

General lectures given at the /I Workshop on Data Analysis in Astronomy Erice, Italy, April 20 - 30, 1986

Editors:

V. Di Gesù

University of Palermo and Institute of Cosmic Physics and Informatics/CNR Palermo, Italy

L. Scarsi

University of Palermo and Institute of Cosmic Physics and Informatics/CNR Palermo, Italy

P. Crane

European Southern Observatory

Garching b. Munchen, Federal Republic of Germany 
Published by

World Scientific Publishing Co. Pte. Ltd.

P. O. Box 128, Farrer Road, Singapore 9128

Library of Congress Cataloging-in-Publication data is available.

\section{SELECTED TOPICS ON DATA ANALYSIS IN ASTRONOMY}

Copyright () 1987 by World Scientific Publishing Co Pte Ltd.

All rights reserved. This book, or parts theoreof, may not be reproduced in any form or by any means, electronic or mechanical, including photocopying, recording or any information storage and retrieval system now known or to be invented, without written permission from the Publisher.

ISBN $9971-50-262-3$

Printed in Singapore by Kyodo-Shing Loong Printing Industries Pte Ltd. 
CONTENTS

Introduction

vii

Information in Astrophysics ..................... 1 V. Casterzani

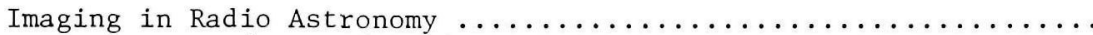

L. Feretti, M. Vigotti

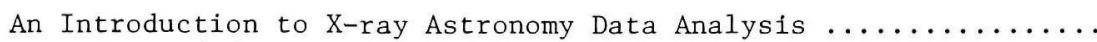
M. Morini

Computational Methods

P. Grosbol

Evolution of Architectures for Data Processing ............. V. Cantoni

Hardware for Graphics and Image Display

I. De Lotto, M. Savini

Data Analysis Systems

D. C. Welzs

Crystal Gazing V. Computer System Technology Projections ....... 153 D. C. WeZzs 
This page is intentionally left blank 


\section{INTRODUCTION}

The main topics covered by the book regard the new developments of the methods and computer architectures in the field of Data Analysis in Astronomy and Astrophysics.

The quality and the style of the contributions are such as to cover the interests of both experts in data analysis and students of an high degree course.

The book is organized in five chapters:

1- Fundamentals of Data Analysis in Astronomy It gives a comprehensive overview of the methodologies used at different wavelength bands from Radio to High Energies, relating the nature of the physical processes to the data treatment.

2- Computational techniques

The chapter deals with the new advanced methods that have been introduced in the analysis of astronomical data in relation to their computational problems.

3- Evolution of architectures for data processing The chapter introduces the concept of parallel processing. Both aspects of architectures and processing are critically explored. A review of the existing parallel computers dedicated to the image processing is presented.

4- Hardware for graphics and image display

In the chapter are presented basic concepts of computer graphics architectures and new developments in the field.

5- Data Analysis systems

The chapter is addressed to the general philosophy and the organizational aspects of the data treatment in Astronomy. Attention is given to evaluate the trend for the sector devoted to work-stations. The expert system development is explored. 